\title{
Imagem, armação, armadilha: \\ o conceito de olhar sob o regime \\ contemporâneo das imagens
}

\author{
Bruno Reiser
}

DOI 10.20396/eha.vil4.3420

As técnicas modernas de reprodução e representação preconizam normas de identificação e socialização que claramente denunciam o significado histórico das teorias da recepção estética e da hermenêutica. O olhar contemporâneo guarda, assim, muito pouco das prerrogativas da contemplação clássica, não menos treinada para esse fim; restringe-se, antes, à percepção apenas reativa e a uma temporalidade vivencial mínima, cuja síntese é a fotografia. ${ }^{2}$ Diante do clamor das imagens, a nada mais se fixa atenção, que apenas transita de uma à outra. Como a abstração é verdadeira precisamente pelo que a falsifica, a imagem desmente o que representa e representa o próprio desmentido. Se a pintura e a escultura, os correlatos da imagem visual, até a apresentação do daguerreotipo em 1839 na França, tinham se desenvolvido como materializações simbólicas do olhar, a fotografia é o representante mais fiel do objetivismo abstrato positivista, focado essencialmente no âmbito da referencialidade, e atinge hoje seu vórtice epocal. Mesmo seus artificialismos, cada vez mais imperantes no cinema e na televisão não o negam, senão que são tentativas de contrafação da desconcertante objetividade fotográfica, subterfúgios que garantem dialeticamente sua predominância. Ao mesmo tempo, devassam os redutos metafísicos do dualismo entre símbolo e natureza, forma e matéria, significante e significado, postos a seu serviço. Seu caráter ideológico consiste no modo como hipostasia a singularidade na individualidade despersonalizada liberal. A imagem revela, então, que essa despersonalização resulta, antes, da inflação do personalismo empreendedor e de sua deterioração a partir das esferas mais altas do poder. ${ }^{3}$

R. Debray observava, a respeito do Estado midiatizado, que "O segredo do poder supremo se manifesta antes nos 'dois corpos do Rei': um, físico, o outro, jurídico. Um carnal, outro simbólico." ${ }^{\text {A }}$

\footnotetext{
1 Doutorando em filosofia na Universidade Estadual de Campinas (UNICAMP). Bolsista do CNPq. Membro do Grupo de pesquisa Metafísica e Política (UNICAMP/CNPq).

2 Cf. TÜRCKE, 2002, pp. 187-201.

3 Serão cada vez menos estranhos casos como João Dória, Governador do Estado de São Paulo, que tem baseado toda a sua propaganda política em um conceito de não-política, do político enquanto gestor, o que mais esclarece a agressividade com que o liberalismo tem adentrado o Estado nas últimas decadas e moldado sua fisionomia. Por princípio, o Estado enquanto empresa submete qualquer regime político a uma política sem povo, não democrática, totalitária: mercado absoluto, Estado totalitário.

4 DEBRAY, 1993, p. 22.
} 
televisão, porém, quebra o veio simbólico, que constitui a aura, os pressupostos moral e intelectual do governenante, ao expô-lo à inadequação de sua própria investidura. "Na videocracia, a personificação (física) tende a arruinar a personificação (moral). A transparência liquefaz a transcendência."5 O regime das imagens desloca a encenação do poder contra sua ética, em um jogo ambivalente que compõe a personificação máxima sobre a dissolução da investidura da soberania e do indívido dela investido. Ele a confronta com sua própria mortalidade e transitoriedade. Porém, seu efeito é o oposto do que se poderia esperar. Ao estancar um instante qualquer em imagem, a reprodução se torna exposição absoluta. As virtudes do mercado e o Estado, enquanto instituição fechada em si mesma, fascista, surgem, então, como única norma, apesar de quem estiver à sua frente: nenhum governante será tão íntegro moralmente quanto os longínquos desbravadores, os bandeirantes da mitologia do liberalismo. Assim, menos importa o governo, e mais o gesto; menos seus atos, e mais seu imperativo moral (nunca efetivo). É enganoso pensar, porém, que a transcendência do Estado desapareça. Antes, ela se transforma ao se alimentar da próprio rejeição que provoca. Em um regime de excessão geral, sua única garantia é a que impede que se torne efetivamente democrático, pois a exclusão é inerente ao seu modo de socialização, instrínseco à sua vivência histórica. ${ }^{6}$ "Um povo é uma duração, cujo fio condutor é mais cultural que material. A era das democracias sem povo eleva a sensação física do efêmero porque rebaixa o tempo coletivo ao lapso de tempo de uma vida individual."7 Vida, cujo princípio de individuação é a imagem técnica. Face a ela o indivíduo se anula, se desmaterializa. Sua psicologia, sua presença própria, se oferecem à transformação midiática como a matéria ao processo de produção. Tal como o homem que pintava a imagem de um bisão na parede da caverna, tentava através dela esconjurar o medo de um bisão real, simular sua presença, o tempo estático da imagem se aproxima das origens da imitação: fazer de uma forma viva, uma forma morta, imóvel, inofensiva. ${ }^{8}$ Mas, também conservar a instância individual de sua iminente dissolução. ${ }^{9}$

Antes de categoria, o tempo é vivenciado enquanto duração não cronológica, quer dizer, sem estar submetido a uma relação. Sua experiência coletiva se constitui primeiramente como ritual. A princípio, no ritual de sacrificio uma comunidade se reunia para co-memorar uma vivência originária, constitutiva. Para, pela representação do gesto primordial, tentar a reparação do irreparável.

\footnotetext{
5 Ibid, p. 26

6 Cf. TÜRCKE, 2002, pp. 60-61; 187.

7 DEBRAY, 1993, p. 45.

8 Cf. TÜRCKE, 2002, pp. 181-82

9 Ibid. p. 186.
} 
Mas, no rito também se constitui a memória. Diz C. Türcke,

Toda a memória é imagem do que não se pode revocar (Unwiederbringlichem). E rituais de sacrifício são imagens, mesmo que imagens muito móveis e agitadas: encenações do terror passado. [...] A representação original é a performática, teatral. A representação mental é, então, esquemática - e logo esquematizante - de sua condensação interior: rememoração de segundo grau. De qualquer modo, porém, rememorar quer dizer elaborar posteriormente. E reelaborado foi primeiramente o terror passado, para que cesse. $O$ passado devia, finalmente, ter passado: não mais dever ser repetido, não mais rememorado. ${ }^{10}$

O surgimento da memória especificamente humana está envolto na tentativa de esquecer através da repetição, como na economia psíquica do indivíduo a pulsão de repetição tenta lidar com o trauma, tranzendo-o de volta, para finalmente se livrar dele, ainda que não o consiga. Há aí um procedimento de racionalização progressiva, da qual nossa civilização é tributária. ${ }^{11} \mathrm{O}$ ritual gesta um tempo longo, uma permanência. Nenhuma substancialidade é filosoficamente pensável sem a experiência primária de algo que subsista.

A temporalidade virtual suplanta as condições transcendentais da intuição espaço-temporal, como à época de Kant e do advento da indústria serial, elas são desairragadas do sujeito empírico. A tautologia entre a substância, enquanto substrato e subsitente, e a permanência (Beharrlichkeit) somente é reconhecida por Kant em seu princípio analógico da experiência do tempo ${ }^{12}$, porque a primazia da substância sobre o acidente aparece também invertida. Sem a substância nada de permanente é conhecido e o tempo não pode ser abstratamente concebido. Não há alteração, mudança, porque não há permanência. Mas, se a subsistência é entendida como o sujeito de nossa experiência temporal, suas determinações devem ser fixas e ela, por sua vez, temporal. ${ }^{13} \mathrm{~A}$ primazia fenomenológica do acidental sobre o substancial expressa-se pela mesma lógica do determinante sobre o determinável e revela sua inadequação categorial. A categoria da relação, pelo uso lógico que dela fazemos, é exterior, como se sobreviesse às já intrinsecas relações entre o determinante e o determinável. ${ }^{14}$ A sobredeterminação da relação manifesta a própria separação entre sujeito transcendental e coisa-em-si, quer dizer, sua base é a ruptura entre o conhecimento abstrato da coisa e o juízo. Ela é primariamente a manifestação da alienação do que está fora, mas é igualmente

\footnotetext{
10 TÜRCKE, 2012, p. 51.

1 Cf. TÜRCKE, 2002, pp. 138 - 149.

$2 \mathrm{KrV}$ B 226/A 183

$13 \mathrm{Krv}$ B 230-31/A 188

14 Krv B 229-30/A 186-87.
} 
produto do pensamento. A racionalização que provê ao desenvolvimento do pensamento abstrato é nostálgica do certa vez perdido.

As técnicas cristalizam tempo em uma produto, seja artístico ou industrial. O regime de produção capitalista, porém, interfere decisivamente nas coisas ao transformá-las em mercadoria. Sua disciplina é fundamentalmente relacional: o tempo de trabalho relativo é sobredeterminado sobre o tempo de vivência do sujeito. A mais-valia é uma forma abstrata de tempo empregado, pelo qual a força de trabalho é convertida em mercadoria. A redução sistemática do tempo de trabalho, socialmente necessário para a produção da mercadoria, à média proporcional de sua troca, abaixo do valor de uso do trabalho alienado, - como a sobredeterminação da relação sobre a subsistência - , está na base do regime de distribuição e da disciplina do trabalho muito além dos muros das antigas fábricas. A diferença se apresenta na maneira como ideologicamente se conforma um excedente de tempo, de trabalho, que não é menos encoberto do que na mercadoria. É condição, para isso, como diz Marx, que "...o vendedor da força de trabalho, como o vendedor de qualquer outra mercadoria, realiza seu valor de troca e aliena seu valor de uso. Ele não pode manter um, sem entregar o outro."15 Mas, na transformação pelo trabalho de valor de uso em valor de troca, novamente, seu detentor também se reduz a uma coisa.

O valor, excetuada sua apresentação apenas simbólica em índice de valor, existe somente em um valor de uso, uma coisa. (O próprio homem, visto como puro existente (Dasein) de força de trabalho, é um objeto natural, uma coisa, ainda que uma coisa também viva, consciente de si, e o próprio trabalho é a externação (Äußerung) dessa força). Perca-se, portanto, o valor de uso, e também se perde o valor. Os meios de produção não perdem seu valor junto com seu valor de uso, pois perdem, de fato, somente a forma originária de seu valor de uso através do processo de trabalho, para ganhar no produto a forma de um outro valor de uso. Mas, é tanto mais importanto para o valor existir em um valor de uso, quanto indiferente em qual ele exista, como mostra a metamorfose das mercadorias. ${ }^{16}$

A produção dissimula cada momento da transformação do valor em seu produto final. Uma árvore precisa perder valor, enquanto árvore, por valor de troca, enquanto madeira, e então por valor de uso para readquirir valor de troca como mesa, cadeira, por exemplo. Os vestígios da alienação persistem, contudo, no próprio trabalhador como seu espectro, sem identidade, sem rosto: como a face negativa do empreendedor liberal. Dispor de sua força de trabalho apenas, significa existir igualmente enquanto matéria que deve ser ocupada, perder valor de uso, tempo. "O tempo é tudo, 
o homem não é mais nada; quando muito, ele é a carcaça do tempo."17

Pelo avanço da robótica e da informática, a despersonalização do trabalho se perfaz com tanto mais eficiência quanto o operador das máquinas se afasta idealmente do que se produz. Como os princípios da razão instrumental vigoram plenamente nas bases do desenvolvimento industrial moderno, seu duplo, a industria da informação dá sentido unívoco a toda a racionalidade. Assim, o operador dessa racionalidade, do computador, menos se distingue do operador da máquina fabril do séc. XIX. Ele se define por sua funcionalidade. Foi M. Heidegger que chamou "armação (Gestell)" ao modo de conformação e configuração metafísica do ser, própria ao império da razão instrumental na modernidade. Um desafio e exigência (Herausforderung) à própria natureza como estocagem de reserva e armazenamento (outro nome para acumulação). "Armação (Ce-stell) se chama o reunir (Versammelnde) daquele regular (Stellen) que o homem regula, i. e., tenta (herausfordert) descobrir o real no modo de dispor (Bestellens) como disponível (Bestand)." 18 Sem enveredarmos nos fatigantes malabarismos verbais de Heidegger, interessa-nos notar que o modo de disposição para a armação e o armazenamento não é apenas o efeito de uma orientação do pensamento, exclusivamente fundado na razão instrumental, mas conforma enquanto tal sua própria valoração e orientação. A técnica recupera, assim, uma potência originária que permanecia velada desde sua separação da arte.

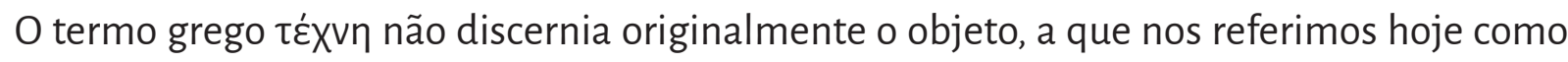
artístico, do técnico. É com a teorização sobre a arte no séc. IV a. C. na Grécia que ambos começam a se desprender com significados distintos, a partir do novo estatuto que a imitação ( $\mu$ í $\mu \eta \sigma ı \varsigma)$ rece-

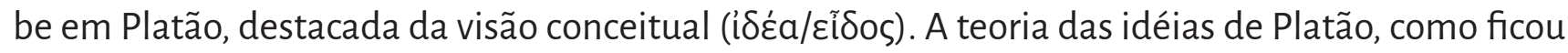
conhecida, é a decantação conceitual da perspectiva na pintura. A representação não é o maior problema das artes, mas sua capacidade de iludir e de perturbar o conhecimento do verdadeiro. Nunca é a distância que o preocupa, mas a inquietante proximidade entre verdade e representação. $\mathrm{Na}$ República, Platão distingue três formas de técnica, de acordo com sua orientação: se voltada para

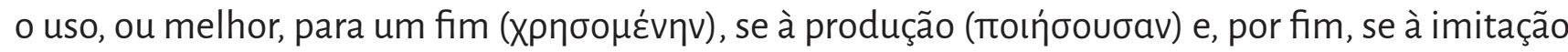

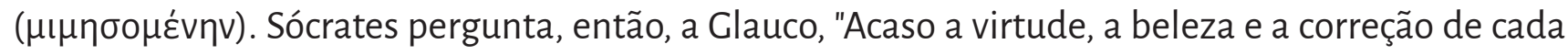
instrumento, de cada vivente e de cada ação volta-se para algo outro que para o seu fim (Xṕ́ıav), para o qual tenha sido produzido ou que é de sua natureza?" À resposta afirmativa, Sócrates prossegue, 
Muito mais necessariamente, aquele que se serve de algo é mais experiente e deve dizer ao produtor o que de bom ou de ruim pode fazer para o uso daquilo de que se serve; [...]. Assim, o fabricante de qualquer instrumento terá uma crença correta sobre o belo e o ruim, ouvindo ao conhecedor e necessariamente obedecendo-lhe, enquanto este (ò $\chi \rho \omega ́ \mu \varepsilon v o \varsigma)$

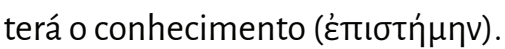

Vem então a invectiva de Sócrates: o imitador, por não conhecer as coisas por sua finalidade, somente as imita e está a um terceiro grau da verdade19. “...ele imitará, sem saber o que é ruim ou

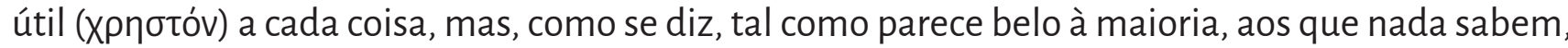
assim o imitará." ${ }^{\text {2o }} \mathrm{O}$ juízo de Platão é, contudo, menos unilateral do que sua interpretação tradicional. À parte algumas vacilações quanto à importância da imitação nos livros II e III da República, foi decisivo para o desdobramento do platonismo, o diálogo Sofista, de composição provavelmente mais recente que o livro X da República. Nele, o discernimento da imitação é tanto mais rigoroso quanto pode ser perigosa a proximidade do sofista com o filósofo. A certa altura, o estrangeiro eleata diz a Teeteto que há na técnica mimética duas formas.

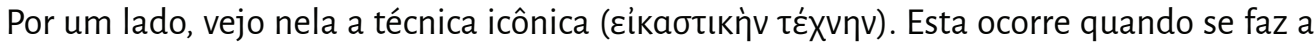

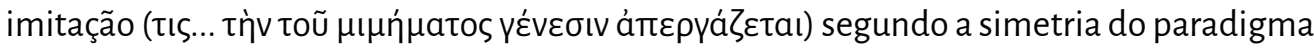
em comprimento, largura e profundidade, e, quanto a isso, dando também as cores que convém a cada coisa. ${ }^{21}$

A esta arte correta, que se atém de perto à norma, ao paradigma, ou seja, à propria idéia, há uma secundária, ilusória, que se chama imitação fantástica, ou imaginativa. "A imitação fantática deriva do modo de produzir uma imagem a partir de como aparece (tò paıvó $\mu \varepsilon v o v$ ) e não de como

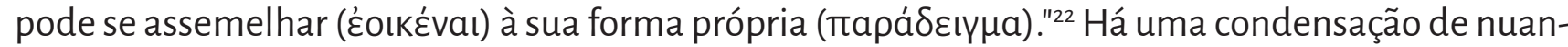
ces aqui difícil de traduzir, mas que será recuperada nas teorias da arte ocidentais. Фaıvó $\mu \varepsilon v o v$, literalmente, o que parece, tem um sentido corrente subjetivo, embora não se distancie tanto de cíkẃv

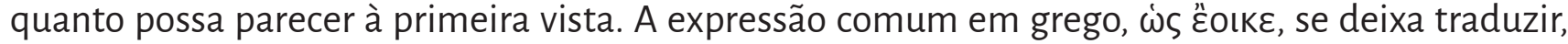
em muitos contextos, por "como parece". Mas sua raiz é a mesma de ícone. Ao distinguir ambos, Platão tinha em vista o que parece ser, mas não é propriamente, e o que parece ser propriamente. A imitação icônica representa a coisa tal como é geometricamente dada, pode-se dizer kantianamente, como é vista sob as condições espaciais da intuição pura. A imitação boa, portanto, é a que segue

\footnotetext{
19 Rep. X 597b

20 Rep. X601d-602b.

21 Soph. 235d-e.

22 Soph. 236 b-c.
} 
um esquema de representação proporcional o mais exatamente possível, em oposição à imitação imaginativa que não necessariamente segue um paradigma, a coisa em sua realidade objetiva. A arte somente tem estatuto de verdade na medida em que remete a um modelo externo, cujo conhecimento próprio cabe à filosofia. Sua capacidade de enunciação da verdade é secundária, porquanto unicamente a filosofia pode dizer o que é a própria arte, qual o estatuto ontológico de suas produções e qual sua finalidade. Trata-se, logo, de dois modos de visão, de olhar. Quem vê através da imitado, não vê exatamente o que é, senão o que é o artístico em si mesmo, e só tangencialmente o que este representa.

A relação entre ideia (forma, paradigma) e matéria prova de tensões, sobreduto depois de Aristóteles, quando a ideia é subjetivada como conceito, expressão mental da essência das coisas. Ainda que a teoria das ideias seja fixada na antiguidade clássica com Cícero e Sêneca como doutrina, e que o neoplatonismo desde Plotino a interprete a partir de uma transcendentalidade radical, o conhecimento filosófico guarda sua primazia frente às obras de arte. No Renascimento, contudo, a prescrição do esquematismo geométrico tomará uma direção decisiva, que trai seus limites metafísicos. Mesmo os artistas de então não apenas produziam arte, mas também refletiram teoricamente sobre sua prática e a ontologia do objeto artístico. É uma característica da época que produtor e imitador, em sentido platônico, se reunam em uma só pessoa. Mas, mais do que isso, artistas como Alberti, Leonardo e Rafael procuraram um modo de composição artística que segue de perto o método indutivo conceitual: a partir do estudo da natureza, compor uma obra ideal. A arte deixa de ser, portanto, mera imitação da natureza, de um modelo exterior, para ser a própria materialização de um ideal natural, que paradoxalmente não está em unidade, mas disperso na natureza. ${ }^{23}$ Em termos próximos aos de Platão no Sofista, Alberti diz que "[...] a beleza é um acordo e uma conspiração das partes que compõem a coisa, conforme um número, uma delimitação e uma disposição definidas e exigidas pela harmonia, isto é, pela razão absolutamente primeira da natureza."24 Embora as concepções da arte e do que seja uma obra de arte variem, a natureza se ergue, nesse momento, como fonte inesgotável de formas que se oferecem ao artista, como território primário de recursos que devem ser reunidos, armados (ge-stellt), à disposição. Com o conceito de natureza, muda também o sentido da referencialidade das coisas que se realiza plenamente com o advento da fotografia no séc. XIX: enquanto a teoria da arte tematiza a imagem como signo, forma 
em que se condensam significante e significado, a referencialidade dissimula a duplicidade entre referência e imagem, forma e matéria, significado e significante e os submete ao seu regime exclusivo de verdade. (A fuga da arte moderna para formas de expressão abstratas parece ser, portanto, uma exigência teórica da própria arte contra o avanço da imagem absoluta.)

Se a transformação do valor na produção se condensa em uma temporalidade objetiva, o produto, o quanto esvazia a temporalidade subjetiva, - o valor de uso do trabalho imediato -, o próprio produto realiza duplamente a função da permanência, da subsistência. Idealmente, enquanto promessa de retomar o que é alienado pela produção, e materialmente enquanto cumpre um valor de uso próprio. Mas, ele nunca poderá suprir a falta como promete - e sequer o pretende mais. Basta se sustentar em sua virtualidade intangível, enquanto projeção, a forma mediada através de sua imagem, da própria coisa. Se a produção, em sua forma de expropriação capitalista, instaurava um círculo de repetição que constitui a própria mercadoria, a propaganda, não menos parte dela, faz-se maior do que aquilo que pretende vender. Pela propaganda as relações de mercado se expressam ideologicamente. O olho, reduzido a suas funções básicas, ol ho que trabalha, é cada vez mais refém do circuito mínimo da atenção, e menos capaz de atender a formas que só se condensam em um tempo longo. Mas, a dissolução das formas, que é o anúncio do colapso do regime da imagem absoluta, retém negativamente a potência reflexiva do olhar.

\section{Referências bibliográficas}

DEBRAY, Régis. L'état séducteur. Paris: Gallimard, 1993.

HEIDEGGER, Martin. Vorträge und Aufsätze. Stuttgart: Klett-Cotta, 2009.

KANT, Immanuel. Kritikder reinen Vernunft, ed. W. Weischedel. Darmstadt: WBG, 1998.

MARX, Karl. Das Kapital I (MEW 23). Berlin: Dietz, 1962.

Miséria da filosofia. São Paulo: Boitempo, 2017.

PANOFSKY, Erwin. Idea. São Paulo: Martins Fontes, 2000.

PLATÃO. Opera I. Oxford: Clarendon Press, 1995.

. Opera IV. Oxford: Clarendon Press, 1978.

TÜRCKE, Christoph. Erregte Cesellschaft. Munique: C. H. Beck, 2002.

Hyperaktiv! Munique: C. H. Beck, 2012. 